\title{
Dielectric properties of Al-substituted Co ferrite nanoparticles
}

\author{
A T RAGHAVENDER* and $\mathrm{K} M$ JADHAV ${ }^{\dagger}$ \\ Department of Electronics and Communication Engineering, Nishitha College of Engineering and Technology, \\ R.R. District 501 359, India \\ ${ }^{\dagger}$ Department of Physics, Dr Babasaheb Ambedkar Marathwada University, Aurangabad 431 004, India
}

MS received 30 October 2008; revised 17 December 2008

\begin{abstract}
A series of polycrystalline spinel ferrites with composition, $\mathrm{CoFe}_{2-x} \mathrm{Al}_{x} \mathrm{O}_{4}(0 \leq x \leq 1)$, have been synthesized by sol-gel method. The effect of Al-substitution on structural and dielectric properties is reported in this paper. X-ray diffraction analysis revealed the nanocrystalline nature in the prepared ferrite samples. The particle size, $D$, decreases with increase in Al-content. The lattice parameter, $a$ and X-ray density, $d_{x}$, decreased with increase in Al-content. The dielectric properties for all the samples have been studied as a function of frequency in the range $100 \mathrm{~Hz}-10 \mathrm{MHz}$. Dielectric properties such as dielectric constant, $\varepsilon^{\prime}$, dielectric loss, $\varepsilon^{\prime \prime}$ and dielectric loss tangent, $\tan \delta$, have been studied for nanocrystalline ferrite samples as a function of frequency. The dielectric constant and dielectric loss obtained for the nanocrystalline ferrites proposed by this technique possess lower value than that of the ferrites prepared by other methods for the same composition. The low dielectric behaviour makes ferrite materials useful in high frequency applications.
\end{abstract}

Keywords. Co-Al-ferrites; sol-gel; nanoparticles; dielectric constant; dielectric loss tangent.

\section{Introduction}

Spinel ferrites are an important class of compounds having large variety of electronic, magnetic and catalytic properties as they possess high resistivity and negligible eddy current losses (Smit and Wijn 1959; Rennard and Khel 1971; Barbes 1995). Nanoferrites are at present very promising materials in technological applications and drug delivery (Mytil Kahn and John Zhang 2001; Sousa et al 2005). Polycrystalline ferrites, which have applications ranging from microwave frequencies to radio frequencies range are very good dielectric materials. The very low conductivity of these materials is suitable for microwave applications. The dielectric properties of these ferrites vary markedly depending upon the preparation techniques. Knowledge of the dielectric properties is also important from the view point of applications at high frequencies.

The sol-gel auto-ignition method is used to speed up the synthesis of complex materials. It is a simple process, a significant saving in time and energy consumption over the traditional methods. Small crystalline size of the resultants may have an important influence on the particles of the materials prepared. This method is employed to obtain improved powder characteristics, more homogeneity and have a narrow particle size, thereby influencing structural, electrical, and magnetic properties of spinel ferrites.

*Author for correspondence (raghavi9@gmail.com)
Cobalt ferrite based nanomaterials are known to be a good candidate for magneto optical recording and very promising for applications in high-density storage (Panda et al 2003; Abo El Ata et al 2004; Zaki 2005). The present study is mainly concerned with experimental results of dielectric properties of $\mathrm{CoFe}_{2-x} \mathrm{Al}_{x} \mathrm{O}_{4}$ nanoparticles. The aim of this work is to study the effect of Al-ions on the behaviour of dielectric properties at different frequencies.

\section{Experimental}

\subsection{Synthesis techniques}

Polycrystalline samples, $\mathrm{CoFe}_{2-x} \mathrm{Al}_{x} \mathrm{O}_{4}(0 \leq x \leq 1)$, were prepared using sol-gel method. High purity nitrates were used for the preparation. The preparation technique is as described elsewhere (Raghavender et al 2007). The obtained nanopowders were pre-sintered at $500^{\circ} \mathrm{C}$ for $5 \mathrm{~h}$ and cooled slowly to room temperature at a rate of $2{ }^{\circ} \mathrm{C} / \mathrm{min}$ to room temperature. The pre-sintered samples were ground and pressed at 4 tons pressure into a disk shape of $12 \mathrm{~mm}$ diameter. A small quantity of polyvinyl alcohol as binding material was added to the powder. The samples were sintered against $500^{\circ} \mathrm{C}$ for $5 \mathrm{~h}$ and slowly cooled at $2^{\circ} \mathrm{C} / \mathrm{min}$.

\section{$2.2 X$-ray diffraction studies}

The structural characterization of the nano particles was carried out using Inel X-ray diffractometer 
$(\lambda=1.78894 \AA)$. The average particle size, $D$, was determined from line broadening of (311) reflection using Scherrer formula

$$
D=\frac{0.9 \lambda}{\beta \cos \theta},
$$

where $\beta$ is the angular line width at half maximum intensity and $\theta$ the Bragg angle for the actual peak.

The X-ray density of all prepared nanoparticles was calculated using the relation

$$
d_{x}=\frac{8 M}{N a^{3}} \mathrm{~g} / \mathrm{cm}^{3},
$$

where $M$ is molecular weight, $N$ the Avogadro number and $a$ the lattice parameter.

\subsection{Dielectric measurements}

Dielectric measurements were carried out at room temperature using 4192A impedance analyser over a wide frequency range from $100 \mathrm{~Hz}$ up to $10 \mathrm{MHz}$. The dielectric constant $\left(\varepsilon^{\prime}\right)$, dielectric loss $\left(\varepsilon^{\prime \prime}\right)$ and loss tangent $(\tan \delta)$ were calculated using the formulas

$$
\begin{aligned}
& \varepsilon^{\prime}=\frac{c d}{\varepsilon_{o} A}, \\
& \varepsilon^{\prime \prime}=\tan \delta \varepsilon^{\prime}, \\
& \tan \delta=\frac{\varepsilon^{\prime \prime}}{\varepsilon^{\prime}},
\end{aligned}
$$

where $c$ is the capacitance, $d$ the thickness of the sample, $A$ the cross-section area, $\varepsilon_{0}$ the free space permittivity.

\section{Results and discussion}

\section{$3.1 X$-ray analysis}

Analysis of X-ray diffraction patterns revealed that all samples have a single-phase cubic structure. As the $\mathrm{Al}$ content increases the width of the central maxima increases and intensity decreases as shown in figure 1. This is due to decrease in particle size of the ferrites as the Al content increases. The grain sizes of the samples were evaluated by measuring the FWHM. The results are as shown in table 1 .

It was found that the lattice parameter, $a$, decreases with increasing Al content. The decrease of the value of lattice parameter with $\mathrm{Al}$ substitution is explained on the basis of ionic radii. When the amount of non-magnetic Al increases, the magnetic moment of unit cell decreases. As the larger $\mathrm{Fe}^{3+}(0.67 \AA)$ ions are replaced by smaller $\mathrm{Al}^{3+}$ $(0.51 \AA)$ ions the lattice parameters decrease and are as given in table 1 .
X-ray density goes on decreasing with increasing $\mathrm{Al}$ content, and this is attributed due to the decrease in lattice constant and particle size.

\subsection{Dielectric constant behaviour}

The dielectric properties of ferrite nanoparticles are influenced mainly by the synthesis technique, grain size, cation distribution etc. Figure 2 displays the variation of dielectric constant, $\varepsilon^{\prime}$, as a function of frequency at room temperature from $100 \mathrm{~Hz}-10 \mathrm{MHz}$. Samples having high d.c. electrical resistivity acquires low values of dielectric constant and vice versa (Amarendra Singh et al 2002; Gul and Maqsood 2008). Generally, dielectric constant, $\varepsilon^{\prime}$, decreases with increasing frequency. The decrease of the dielectric constant, $\varepsilon^{\prime}$, with $\mathrm{Al}$ ions substitution can be explained on the basis of the mechanism of polarization process in ferrites, which is similar to that in the conduction process. The whole polarization in ferrites is mainly contributed by the space charge polarization, which is governed by the number of space charge carriers and the conductivity in materials (Mytil Kahn and John Zhang 2001) and hopping exchange of the charges between two localized states governed by density of the localized state and resultant displacement of charges w.r.t. the external field. The addition of $\mathrm{Al}$ ions reduces the iron ions on $\mathrm{B}-$ sites, which is mainly responsible for both space charge polarization and hopping exchange between the localized states. Therefore, increasing of Al ions content causes a decrease in the polarization, which is accomplished by a decrease of dielectric constant, $\varepsilon^{\prime}$, of the composition. Koops (1951) proposed that the effect of grain boundaries is predominant at lower frequencies. The thinner the grain boundary, the higher the dielectric constant value is. The decrease in dielectric constant with increasing frequency is attributed to the fact that the electron exchange between $\mathrm{Fe}^{2+}$ and $\mathrm{Fe}^{3+}$ ions cannot follow the

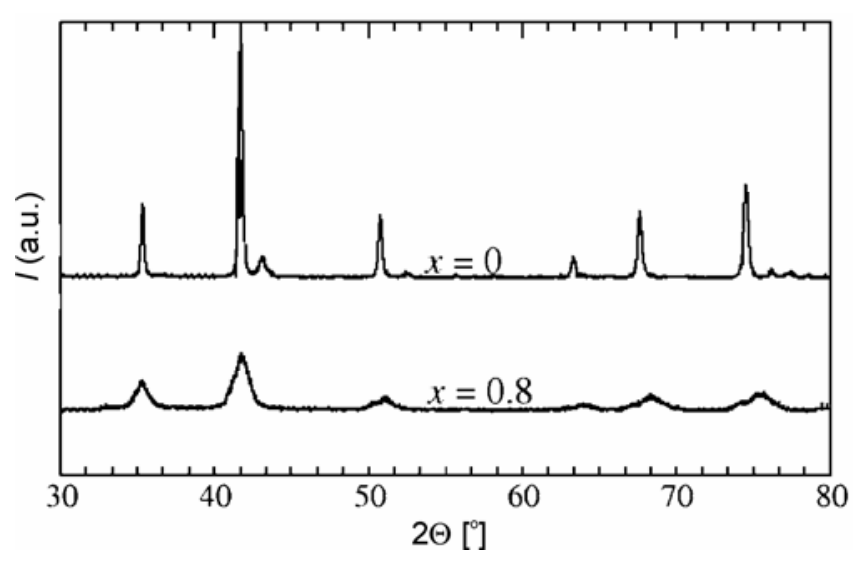

Figure 1. Typical X-ray diffraction patterns for typical samples $(x=0 \cdot 0$ and $0 \cdot 8)$. 
Table 1. Particle size, $D, \mathrm{~nm}$, lattice parameter, $a(\AA), \mathrm{X}$-ray density, $d_{x}$ are shown

\begin{tabular}{lccc}
\hline Composition & $\begin{array}{c}\text { Particle size, } \\
D(\mathrm{~nm})\end{array}$ & $\begin{array}{c}\text { Lattice parameter, } \\
a(\AA)\end{array}$ & $\begin{array}{c}d_{x} \\
\left(\mathrm{~g} / \mathrm{cm}^{3}\right)\end{array}$ \\
\hline $\mathrm{CoFe}_{2} \mathrm{O}_{4}$ & 39 & $8 \cdot 335$ & $5 \cdot 384$ \\
$\mathrm{CoFe}_{1 \cdot 8} \mathrm{Al}_{0 \cdot 2} \mathrm{O}_{4}$ & 37 & $8 \cdot 334$ & $5 \cdot 254$ \\
$\mathrm{CoFe}_{1 \cdot 6} \mathrm{Al}_{0.4} \mathrm{O}_{4}$ & 28 & $8 \cdot 321$ & $5 \cdot 145$ \\
$\mathrm{CoFe}_{1 \cdot 4} \mathrm{Al}_{0 \cdot 6} \mathrm{O}_{4}$ & 24 & $8 \cdot 302$ & $5 \cdot 047$ \\
$\mathrm{CoFe}_{1 \cdot 2} \mathrm{Al}_{0.8} \mathrm{O}_{4}$ & 8 & $8 \cdot 202$ & $5 \cdot 095$ \\
$\mathrm{CoFeAlO}_{4}$ & 6 & $8 \cdot 184$ & 4.988 \\
\hline
\end{tabular}

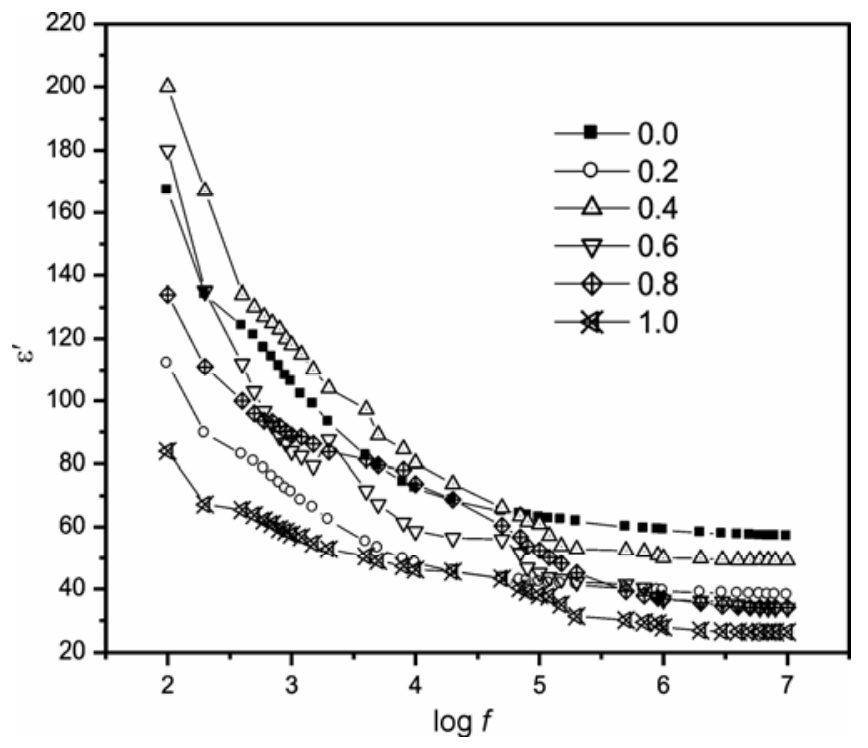

Figure 2. Dielectric constant $\left(\varepsilon^{\prime}\right)$ for the samples $\mathrm{CoFe}_{2-x}$ $\mathrm{Al}_{x} \mathrm{O}_{4}(0 \leq x \leq 1)$.

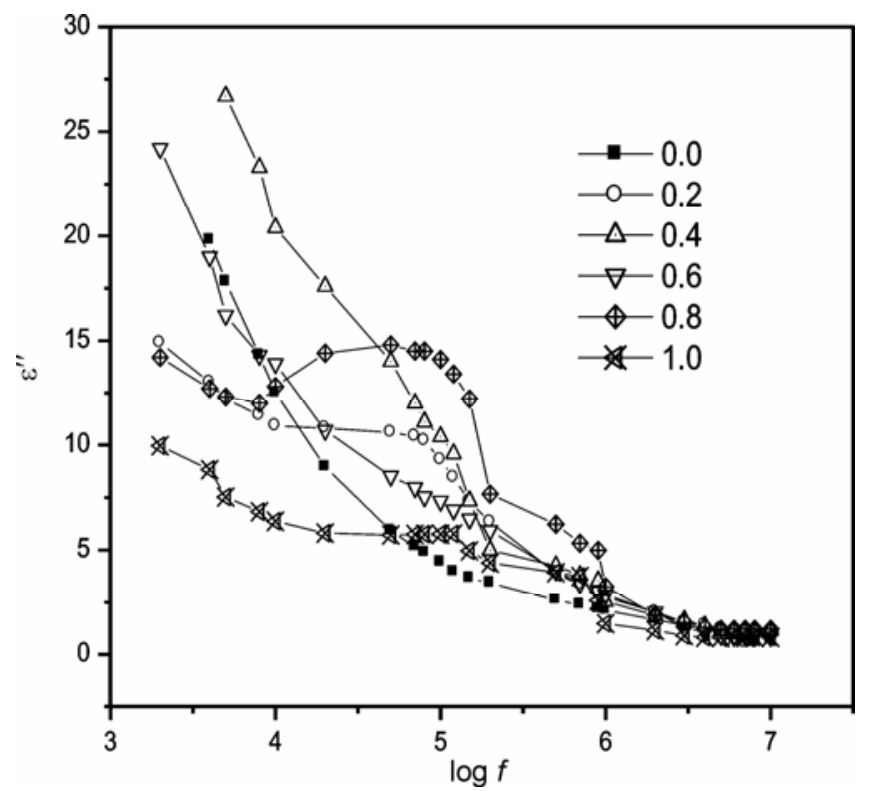

Figure 3. Dielectric loss factor $\left(\varepsilon^{\prime \prime}\right)$ for the samples $\mathrm{CoFe}_{2-x}$ $\mathrm{Al}_{x} \mathrm{O}_{4}(0 \leq x \leq 1)$.

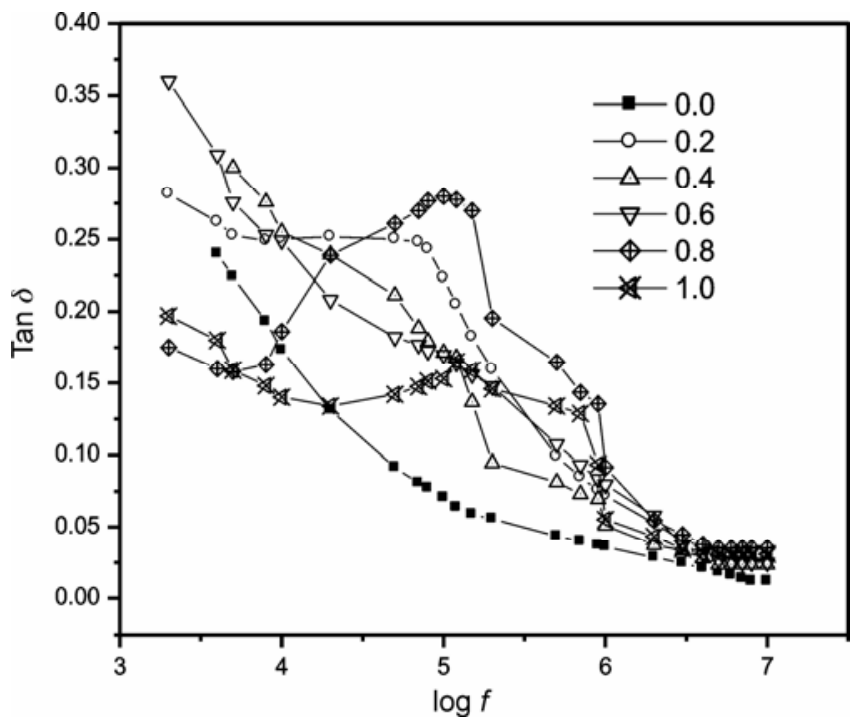

Figure 4. Dielectric loss tangent $(\tan \delta)$ for the samples $\mathrm{CoFe}_{2-x} \mathrm{Al}_{x} \mathrm{O}_{4}(0 \leq x \leq 1)$.

change of the external applied field beyond certain frequency (Abo El Ata et al 2004). The value of the dielectric constant is very high at lower frequencies and decreases with increasing frequency. At lower frequencies the grain boundaries are more effective than grain electrical conduction. Similar low values of the dielectric constant were found in $\mathrm{Mn}$ substituted $\mathrm{Ni}-\mathrm{Zn}$ ferrites prepared by citrate method (Amarendra Singh et al 2002) and $\mathrm{Cd}, \mathrm{Cr}$ substituted Co ferrite (Shitre et al 2002) etc.

\subsection{Dielectric loss factor}

The dielectric loss factor, $\varepsilon^{\prime \prime}$, is as displayed in figure 3 . The dielectric loss factor is considered to be the most important part of the total core loss in ferrites (Brockman et al 1949; Mangalaraja et al 2002). The dielectric loss pattern is seen to be similar to that of dielectric constant. Thus the dielectric and dielectric loss obtained for the present nanoferrites prepared by sol-gel method possess lower value than that of the ferrites prepared by conventional ceramic method for the same composition. The low dielectric values make these ferrites to be used in the higher frequency applications. 


\subsection{Dielectric loss tangent}

Figure 4 displays the variation of dielectric loss tangent, $\tan \delta$, as a function of composition as well as frequency for all the samples. A small abnormal behaviour was observed for all samples at lower frequencies. According to Rezlescu model the relaxation peak may be due to the collective contribution of both $p$ and $n$ type carriers (Rezlescu and Rezlescu 1974; Gul and Maqsood 2008). The electronic exchange between $\mathrm{Fe}^{2+} \Leftrightarrow \mathrm{Fe}^{3+}$ and hole transfer between $\mathrm{Co}^{2+} \Leftrightarrow \mathrm{Co}^{3+}$ in octahedral sites are responsible for such behaviour. Furthermore the jumping frequencies of localized charge carriers are almost equal to that of the applied a.c. electric field. The low dielectric parameters obtained for the present samples attributed to be more homogeneous and structurally perfect ferrites prepared by sol-gel method. The decrease in dielectric loss tangent with change in the composition and frequency is in accordance with Koops phenomenological model (Koops 1951).

\section{Conclusions}

Co-Al ferrites $(0 \leq x \leq 1)$ were prepared by the sol-gel method. The particle size, $D$, of all the samples decreases with increase in Al-content. The lattice constant, $a$, decreases with increase in Al-content due to smaller ionic radii of $\mathrm{Al}$ ions than $\mathrm{Fe}$ ions. The sol-gel prepared samples are found to exhibit lower values of the dielectric constant and losses as compared to those obtained in ferrites prepared by the conventional ceramic method. Dielectric constant and loss decreases rapidly with increasing frequency, and then reaches a constant value. Hence much lower dielectric constants obtained for the ferrites are used in the applications at high frequencies as microwave absorbers.

\section{Acknowledgements}

One of the authors (ATR) would like to thank Prof. Vijay Kumar, Director, Nishitha College of Engineering and Technology, Lemoor (Vill), Kadukur (M), R.R. District, Greater Hyderabad, for support and Prof. G Markandeyulu and K Kamala Bharathi, Department of Physics, Indian Institute of Technology Madras, Chennai, for providing dielectric measurements.

\section{References}

Abo El Ata A M, Attia S M and Meaz T M 2004 Solid State Sci. 661 Amarendra Singh K, Goel T C, Mendiratta R G, Thakur O P and Chandra Prakash 2002 J. Appl. Phys. 916626

Barbes V A M 1995 in Progress in spinel ferrite research (ed.) H K J Buschow (Amsterdam: Elsevier)

Brockman F G, Dowling P H and Steneck W G 1949 Phys. Rev. 751440

Gul I H and Maqsood A 2008 J. Alloys Compds 465227

Koops C 1951 Phys. Rev. 83121

Mangalaraja R V, Ananthakumar S, Manohar P and Gnanam F D 2002 J. Magn. Magn. Mater. 25356

Mytil Kahn L and John Zhang Z 2001 Appl. Phys. Lett. 78365

Panda R N, Shih J C and Chin T S 2003 J. Magn. Magn. Mater. 25779

Raghavender A T, Damir Pajic, Kreso Zadro, Tomislav Milekovic, Venkateshwar Rao P, Jadhav K M and Ravinder D 2007 J. Magn. Magn. Mater. 1316

Rennard R J and Khel W L 1971 J. Catal. 21282

Rezlescu N and Rezlescu E 1974 Phys. Status Solidi (a) 23575

Shitre A R, Kawade V B, Bichile G K and Jadhav K M 2002 Mater. Letts 36188

Sousa E C, Alves C R, Aquino R, Sousa M H, Goya G F, Rechenberg H R, Tourinho F A and Depeyrot J $2005 \mathrm{~J}$. Magn. Magn. Mater. 289118

Smit J and Wijn H P J 1959 'Ferrites' physical properties of ferrimagnetic oxides in relation to their technical applications (Eindhoven: Phillips)

Zaki H M 2005 Phys. B363 232 